\title{
"ENFOCAR NUESTRA TRINCHERA". EL SURGIMIENTO DEL CINE INDÍGENA EN LA PROVINCIA DEL CHACO (ARGENTINA)
}

\author{
"Focusing our trench". The rise of indigenous cinema in the Chaco province \\ (Argentina)
}

Carolina Soler*

\section{Resumen}

Este artículo propone un recorrido por diferentes hechos sociales y políticos que contribuyeron a la formación de un espacio de cine indígena en el entramado estatal de la provincia del Chaco. Tras brindar un panorama regional para entender el surgimiento de los medios indígenas en Latinoamérica, destaca tres hitos claves que hicieron posible el surgimiento de este cine en dicha provincia, articulando lo que ocurría a nivel local, nacional y continental. Finalmente, en el marco del cine, reflexiona acerca del vínculo entre indígenas, Estado y colonialismo.

$<$ Video indígena $><$ Provincia de Chaco $><$ Medios indígenas $><$ Cine latinoamericano $>$

\begin{abstract}
This article examines different social and political events that led to the formation of an Indigenous Cinema Space within the State in the province of Chaco. After providing a regional overview to understand the emergence of Indigenous Media in Latin America, this article highlights three key milestones that made possible the emergence of this cinema in the province of Chaco, articulating what happened at local, national and continental level. Finally, it reflects on the link between indigenous people, State and colonialism within the framework of cinema.
\end{abstract}

$<$ Indigenous Video $><$ Chaco Province $><$ Indigenous Media $><$ Latin-American Cinema $>$

Recibido: 18/02/2017//Aceptado: 22/03/2017

\begin{abstract}
Abordaje
En el año 2008, en el entramado estatal de la provincia del Chaco, surgía un espacio de formación audiovisual para indígenas; este hecho, precursor en Argentina, se articulaba con otras experiencias similares que ocurrían a nivel internacional, en un marco político nacional en el que el desarrollo de la comunicación audiovisual recibía un

\footnotetext{
* Becaria doctoral de CONICET. Doctoranda en Antropología en cotutela por la Universidad de Buenos Aires y la École des hautes études en sciences sociales (EHESS) de París. Magíster en Antropología y Etnología por la EHESS. Licenciada en Antropología por la UNLP carolinasolerc@gmail.com
} 
especial apoyo. En este artículo busco arrojar algo de luz en torno a esos primeros pasos del cine indígena chaqueño, haciendo foco en los actores sociales locales, indígenas y no indígenas, quienes generaron alianzas y rupturas con los otros niveles antes mencionados. Para ello será necesario poner la experiencia chaqueña en un contexto más amplio y analizar cómo se constituyeron en Latinoamérica distintos centros de producción audiovisual indígena, asociados a lo que se dio a llamar "movimiento panindígena"1 (Jackson y Warren, 2005; Salazar, 2002; Schiwy, 2010).

Desde 2010 me he acercado a distintas experiencias de cine indígena; a algunas de ellas, desde la lectura bibliográfica y el visionado de filmes, y a otras, desde la experiencia de campo. Tuve la oportunidad de trabajar hibridando mi tarea antropológica con la enseñanza de cine; primero con comunidades shuar (jíbaros) de la Amazonía ecuatoriana en 2014 y luego, desde marzo de 2015 hasta octubre de 2016, con comunidades principalmente qom (tobas) de la provincia del Chaco. El análisis que aquí me propongo forma parte de mi investigación doctoral en antropología y comprende algunas reflexiones que espero desarrollar más extensamente durante la escritura de mi tesis.

Este artículo se origina en los relatos en primera persona de algunos de los protagonistas locales que hicieron posible la puesta en marcha del cine indígena en Chaco: Marcelo Pérez, fundador y primer director del Departamento de Cine y Espacio Audiovisual del Chaco, que albergó el Área de Cine Indígena — primera en el país-; Juan Chico, referente qom (toba) que estuvo al frente de esa área desde su formación hasta 2015; Bashe Charole, referente y comunicadora qom que desde mediados de los años 1990 trabaja en proyectos de comunicación indígena, primero radiales y luego audiovisuales; y Lecko Zamora, referente wichi (mataco) que acompañó sostenidamente espacios vinculados al arte y cine indígenas en la provincia del Chaco ${ }^{2}$. Las fuentes para la redacción de este artículo han sido los relatos de estas personas, así como también artículos periodísticos que han brindado precisiones sobre fechas y nombres que se escapaban a la memoria en el relato oral. También fue imprescindible visionar algunos filmes (citados al final de la bibliografía), para poder comprender la categoría "cine indígena" con la singularidad con la que fue apropiada en esa provincia.

Principalmente buscaré analizar los contextos, a nivel internacional, nacional y local $^{3}$, que acompañaron a la formación de un área de cine indígena en la provincia del Chaco. Mucho quedará por decir sobre cómo este espacio se fue transformando,

\footnotetext{
1 Movimiento surgido en los años 1980 y consolidado en los años 1990 en torno a la conmemoración de los 500 años de la llegada de los primeros colonizadores europeos a América.

2 Agradezco a cada una de estas personas, quienes, a través de los años, con y sin grabador mediante, compartieron historias sobre cine, luchas y militancias sociales; su mirada crítica y aguda ha transformado sustancialmente mis reflexiones y ha abierto nuevos sentidos a mi investigación. También debo agradecer a Viyen Leiva, comunicador qom con quien compartí varios encuentros y quien me invitó a El Impenetrable chaqueño en diciembre de 2014 para acompañar algunas proyecciones en torno al cine indígena en el marco del festival Anaconda; aunque no guardé un registro sonoro de nuestras largas conversaciones, sus historias marcaron mi visión sobre Chaco, su cine y su gente.

3 Con el término local hago referencia principalmente a acontecimientos que ocurrieron en la provincia del Chaco. Utilizo "local" en vez de "provincial" para no confundir las trayectorias de los actores con las políticas provinciales, aunque estos dos elementos se articulan en varias ocasiones.
} 
debilitando y fortaleciendo con los cambios políticos y con las disputas internas de los comunicadores indígenas que trabajan en cine. Varias cuestiones tensionan este relato: ¿cómo se articulan las luchas que sostienen comunicadores indígenas en distintas partes de las Américas con lo que ocurre en Chaco a nivel local?, ¿en qué sentidos puede el cine ser considerado una herramienta de lucha?, ¿considerar el cine indígena como un cine militante implica imponer una función externa a las ontologías indígenas chaqueñas?, ¿cómo se sostienen las prácticas por fuera o por dentro del Estado?, ¿cómo resuelven distintos grupos indígenas la articulación en tensión con los Estados provincial y nacional para llevar adelante sus demandas y reivindicaciones?

\section{Medios indígenas, un panorama americano}

Cuando estaba comenzando a escribir este artículo recibí la triste noticia de que la organización Vídeo nas aldeias, con más de 30 años de experiencia formando cineastas indígenas a lo largo y ancho de Brasil, corría serios riesgos de tener que cerrar sus puertas y quedar reducida su página web, bajo las nuevas políticas de Estado de ese país y a la pérdida progresiva de apoyo financiero internacional ${ }^{4}$. Treinta años no es poco tiempo para sostener proyectos de este tipo, "imperceptibles" en el sentido de la poca visibilidad de las minorías que representan, en Estados nación que miran a otro lado y que cada vez que se les habla de los indígenas prefieren imaginarlos con plumas y taparrabos.

Las sociedades colonialistas, a través del cine (Gustavsonn y Giordano, 2013; Wilson y Steward 2008; Raheja, 2013), la fotografía (Edwards, 1997; Giordano, 2004, 2012 y 2013, Butto, 2012) y la literatura (Vickers, 1998), han construido históricamente una imagen del indígena a su antojo, y el hecho de que los propios indígenas aprendan a utilizar las herramientas de representación de Occidente puede ser entendido como un paso hacia la autodeterminación, aunque, como se discute en este artículo, una apropiación de ese tipo involucra procesos complejos que vale la pena analizar detenidamente. En 2008, cuando en Chaco comenzaban a dictarse talleres de cine, salía a la luz el libro Global indigenous media: cultures, poetics and politics, en el que Pamela Wilson y Michelle Stewart reunieron artículos en torno a los usos de los medios de comunicación indígenas en los cinco continentes. ${ }^{5}$ Esto nos da la perspectiva para ver que ya en ese momento una gran diversidad de pueblos indígenas se había apropiado de distintas herramientas audiovisuales, con procesos singulares en cada región del globo. También nos da la pauta de que para analizar el cine indígena en Argentina - específicamente en Chaco - hay que realizar un alejamiento de escala para comprender su anclaje en ese entorno internacional.

\footnotetext{
${ }^{4}$ Más información disponible en: https://www.nexojornal.com.br/expresso/2016/11/25/O-que-é-oprojeto-'V\%C3\%ADdeo-nas-Aldeias'-e-por-que-ele-está-ameaçado

5 Esta compilación no fue la primera; antes, Lila Abu-Lughod, Faye Ginsburg y Brian Larkin (2002) habían abierto la discusión, con el libro Media Worlds: Anthropology in a New Terrain, en torno a la formación de un nuevo campo en antropología: la antropología de los media (media anthropology). Allí habían reunido trabajos acerca de ese nuevo "terreno", entre los que podemos encontrar algunos artículos ya clásicos sobre cine indígena (Ver: Terence Turner y F. Ginsburg). Lo que se proponían los autores era visibilizar y agrupar las experiencias antropológicas en torno al estudio de los medios de comunicación.
} 
Estas apropiaciones de los medios audiovisuales, que todavía hoy siguen pareciendo novedosas, acaban de cumplir medio siglo. Un punto de partida posible ha sido la iniciativa comandada por Sol Worth, John Adair y Richard Chalfen, cuando en junio de 1966 enseñaron a los indios navajos (diné) a utilizar cámaras de $16 \mathrm{~mm}$ (Worth y Adair, 1970 y 1972). Esta primera experiencia experimental, que Worth clasificó como "antropología de la comunicación visual" (1981), se tituló Navajo Film Project y quedó atrapada en el marco de una investigación antropológica cuyos resultados se volcaron en el resonante libro Through Navajo Eyes (Worth y Adair, 1972). Es notorio que con el correr de los años tuvo mayor eco el hito de dar un primer paso hacia un cine participativo, que los resultados de una investigación en la que se pretendía buscar la "gramática" visual "universal" predicada por Chomsky en los años 1960 (Chomsky, 1979). De todas formas, los siete cortometrajes agrupados bajo el título Navajo Film Themselves $^{6}$, que por mucho tiempo han sido de muy difícil acceso ${ }^{7}$, fueron recientemente recuperados y restaurados - ese material pudo ser proyectado en 2012 frente a algunos de sus realizadores y sus familias - Los primeros cineastas navajos fueron Mike Anderson, Al Clah, Susie Benally, Johnny Nelson, Mary Jane Tsosie, Maxine Tsosie y Alta Kahn (Peterson, 2013).

Pero, más allá del hito inaugural que significó la experiencia de los navajos de Arizona, el video indígena como movimiento social tiene otro desarrollo histórico. Antes de avanzar sobre ello, debo aclarar que utilizo principalmente el término cine y no video a lo largo de este artículo, porque así se denomina a esta práctica audiovisual en la provincia del Chaco, tanto en los festivales como en los talleres y espacios de producción en los que he trabajado. De todos modos es importante remarcar - como lo proponen Francisco Salazar y Amalia Córdova (2008) — que la expresión video indígena fue apropiada y resignificada en Latinoamérica como una posición política crítica, con miras a la autodeterminación y revitalización cultural de muchos pueblos, y que bajo esa denominación se ha ido formando una corriente en torno a la realización audiovisual a lo largo del continente americano ${ }^{8}$. En cuanto al surgimiento de esta corriente, Salazar y Córdova refieren que:

\footnotetext{
${ }_{6}$ Navajo Film Themselves (Los navajos se filman a sí mismos) incluyó los cortometrajes Intrepid Shadows (Sombras intrépidas), de Al Clah; The Navajo Silversmith (El navajo orfebre), de Johnny Nelson; A Navajo Weaver (La tejedora navajo), de Susie Benally; Old Antelope Lake (El antiguo lago antilope), de Mike Anderson; Second Weaver (Segunda tejedora), de Alta Kahn; The Shallow Well Project (El proyecto del pozo plano), de Johnny Nelson, y The Spirit of Navajos (El espiritu de los navajos), de Maxine Tsosie y Mary Jane Tsosie.

7 Hasta hace algunos años se los conservaba sólo en formato analógico de $16 \mathrm{~mm}$ en el Center for Mass Communication de la Universidad de Columbia y en la Biblioteca del Congreso de los Estados Unidos.

8 No hay un término unificado que haga referencia a la apropiación de herramientas audiovisuales por parte de los indígenas. En Brasil, por ejemplo, se habla de vídeo índio (Carelli, 2011); en Estados Unidos, de indigenous media (Ginsburg, 1991), y en México, de video indigena (Wortham, 2013). En Nueva Zelanda, los maoríes hablan sencillamente de cine (Gauthier, 2008), aunque es cierto que sus realizaciones son más cercanas al cine industrial. Como alguna vez dijo Claude Chavrol, "un cinéaste ne mérite ce nom que du moment où il sait qu'il fait" (Aumont, 2011). En ese sentido, el término "cine" puede ser anclado en un saber, una decisión o una acción realizativa, lo que abre un espacio amplio desde el punto de vista creativo. Igualmente, no descuidamos las importantes raíces históricas del término "video indígena" en el contexto latinoamericano.
} 
"el surgimiento, en los últimos veinte años, del video indígena en Latinoamérica no está confinado al legado de los métodos participativos del cine etnográfico ni al interés de algunos realizadores de cine etnográfico en las luchas de los indígenas por la supervivencia cultural. Este primer impulso provino del trabajo antropológico realizado desde las ONG de comienzos de los años 1980 - y no sólo de los cineastas etnográficos que trabajaban a nivel comunitario- - que percibían el interés y la demanda particular de los activistas indígenas hacia las radios y el video como instrumentos de acción política" (Ibíd.: 44)9.

A lo que principalmente se refieren estos autores es a las iniciativas que se sostuvieron en el tiempo desde finales de los años 1980 (Salazar y Córdova, 2008; Córdova, 2011, Schiwy, 2009) y a los centros más prolíficos en cuanto a la realización y la distribución de video indígena, que se encuentran en el sur de México, en Bolivia y en Brasil (en estos países se han establecido importantes programas de comunicación y formación audiovisual). En Brasil y en Bolivia, por ejemplo, organizaciones como Video nas Aldeias (Video en las aldeas)(Carelli, 2011 y 2013; De Carvalho et al, 2011) y el Centro de Formación y Realización Cinematográfica (CEFREC) (Zamorano, 2009, s.f.; Schiwy, 2009), respectivamente, han diseñado y perfeccionado métodos de enseñanza que permitieron la puesta en marcha de escuelas itinerantes de formación de cineastas indígenas a lo largo y ancho de estos países; en la actualidad hay cineastas indígenas suficientemente formados para impartir ellos mismos estos conocimientos.

Otras experiencias se pueden encontrar en Ecuador y en Colombia y, en menor escala, en Chile, Argentina y Paraguay. La Confederación de Nacionalidades Indígenas de Ecuador (CONAIE), por ejemplo, posee su propio departamento de comunicación (Schiwy, 2009) además, en ese mismo país, organizaciones más pequeñas han trabajado durante los últimos años para brindar herramientas audiovisuales a comunidades indígenas, como el caso de El Churo Comunicación y Etsa-Nantu/Cámara-Shuar. Los kichwas amazónicos de Sarayaku tienen su propia productora de cine y cuentan con realizadores de renombre internacional, como Eriberto Gualinga, Alberto Muenala, kichwa de la sierra, es otro cineasta ecuatoriano muy activo. En Colombia, el Consejo Regional Indígena del Cauca (CRIC) es uno de los focos de mayor producción audiovisual de ese país, sobre todo a partir de la labor del pueblo nasa (Schiwy, 2009). Las producciones audiovisuales indígenas se han ido articulando paulatinamente a través de festivales y redes virtuales que se integran a nivel mundial con la participación de otros pueblos y colectivos, como los afrodescendientes, las personas desplazadas y otras minorías (Córdova, 2011).

La apropiación de los medios de comunicación no es un hecho aislado, sino que forma parte de procesos de autodeterminación movilizados por luchas y reivindicaciones de distintos pueblos. Estos movimientos reivindicativos surgieron a mediados de los años 1980 y confluyeron a comienzos de los 1990 cuando muchos indígenas se

\footnotetext{
9 La traducción es propia.
} 
negaron a aceptar los festejos por el quinto centenario de la llegada de los colonizadores europeos a América, lo que fue tomado, siguiendo al antropólogo chileno José Bengoa (2009: 8), como "símbolo de resistencia y reconstrucción de sus identidades étnicas". El cambio de década fue testigo de muchas movilizaciones, principalmente en los países con mayor presencia indígena, como Ecuador, México o Bolivia. En ese marco se creó en 1985 la Coordinadora Latinoamericana de Cine de los Pueblos Indígenas (CLACPI), organizada en la Ciudad de México durante el "I Festival Latinoamericano de Cine y Video de los Pueblos Indígenas”. A partir de la aparición de esa coordinadora, distintos colectivos de comunicación comenzaron a organizar festivales generalmente bianuales en distintos países latinoamericanos ${ }^{10}$.

En la medida en que algunas experiencias fueron cobrando visibilidad, como la de los kayapo Mekaron Opoi D’joi (El que crea las imágenes), iniciada por Mônica Frota en 1987 y continuada por el antropólogo norteamericano Terence Turner (Turner, 1990 y 1992), los festivales de la CLACPI, en sus selecciones y premiaciones, comenzaron a ponderar el proceso de realización audiovisual — la poética, siguiendo la etimología de la palabra poiesis - por sobre la estética audiovisual, con la idea de mostrar la producción de un cine enraizado socialmente (Córdova y Salazar, 2008). Se empezó a premiar filmes que no necesariamente respondieran a los cánones estéticos de la industria occidental — ni apuntaran a la excelencia técnica-, pero que estuvieran atravesados por procesos de realización que involucraran lo comunitario o dieran testimonio de procesos políticos y sociales. De ahí que varios autores ${ }^{11}$ plantearan repensar el cine indígena como una continuidad del cine revolucionario de los años 1960 y 1970 ${ }^{12}$, al que denominarían video imperfecto, como lo propone el manifiesto del cubano García Espinosa (1970). El video imperfecto es un tipo de medio audiovisual que escapa a los cánones occidentales de la perfección: "los medios imperfectos suponen una búsqueda constante de nuevos lenguajes, lenguajes despreocupados por la perfección técnica o por las reglas convencionales de los modos de representación y narración" (Córdova y Salazar, 2008: 501 ${ }^{13}$.

\section{Tres hitos claves para comprender el surgimiento del cine indígena en el Chaco}

Al principio de 2008 se empezó a gestar un espacio audiovisual para indígenas en el marco institucional de la Subsecretaría de Cultura del Chaco ${ }^{14}$. En ese ámbito comenzó el dictado de talleres de formación audiovisual y se creó el festival de cine, que

${ }^{10}$ Los festivales internacionales de la CLACPI tuvieron lugar en México (1985), Brasil (1987), Venezuela (1990), Perú (1992), Bolivia (1996), Guatemala (1999), Chile (2004), México (2006), Bolivia (2008), Ecuador (2010), Colombia (2012) y Chile-Argentina [Wallmapu] (2015). Fuente: http://www.clacpi.org/ actividades/festivales-internacionales/que-son/

${ }^{11}$ Ver: Córdova, 2011; Córdova y Salazar, 2008; Salazar, 2004, Schiwy, 2009; Zamorano, 2009.

12 Ver: García Espinosa: "Por un cine imperfecto" (1982 [1970]); Gluber Rocha: "Una estética del hambre" (1965) y Fernando Solanas y Octavio Getino: "Hacia un tercer cine" (1966).

${ }^{13}$ La traducción es mía.

${ }^{14}$ Ver: más adelante el desarrollo de esa subsecretaría y las distintas denominaciones de los espacios de cine que albergó en su interior. 
tuvo continuidad, año tras año, hasta el presente. Producto de los talleres se han rodado películas de ficción y documentales, algunas aún sin editar y otras que han sido estrenadas en pantalla grande y consagradas por un público pequeño pero cautivo. A través de los festivales de cine se fue compilando material para formar una videoteca de más de cien películas en torno a la temática indígena, que en los últimos años se han proyectado de forma itinerante por la provincia. En cuanto a la singularidad de esta iniciativa, es importante remarcar dos aspectos: por un lado, que se trata de un fenómeno precursor en Argentina — mismo si es posible encontrar realizadores y colectivos de cine indígena a lo largo del país, no existen otras provincias donde haya surgido un espacio institucional estatal que brinde cámaras y asesoramiento a la población indígena de esta formaPor otro lado, si algo caracteriza a los proyectos estatales, al menos en Argentina, es que son difíciles de sostener en el tiempo: el apoyo político — y económico — suele ser fluctuante según los vaivenes institucionales y los cambios de gestión.

En Chaco, estos espacios de formación audiovisual estuvieron en gran parte vinculados al Estado provincial y, más específicamente, se originaron junto a la creación del Instituto de Cultura del Chaco $^{15}$ (ex Subsecretaría de Cultura). La estructura del Estado, que estabiliza temporariamente sus políticas es atravesada por activistas indígenas y no indígenas-, políticos y artistas cuyo trabajo fue imprescindible para la creación del espacio de cine indígena. Sin un análisis de las trayectorias personales de estos actores sería imposible comprender el surgimiento de los espacios institucionales que dieron acceso al cine como "tecnología de mediación", parafraseando a Faye Ginsburg (2011: 241).

Al abordar el cine indígena en el marco del Estado provincial no estoy asumiendo que no podamos encontrar otros tipos de expresiones independientes — yo misma trabajé con comunidades qom fuera de todo tipo de estructura estatal e institucional- Los indígenas chaqueños han aprendido a vincularse y desvincularse del Estado generando estrategias de subsistencia y espacios de trabajo y reivindicaciones en un nudo de relaciones siempre complejas, $\mathrm{y}$, como mostraré más adelante, existen intentos de los propios indígenas de generar organizaciones de comunicadores audiovisuales por fuera de la estructura estatal.

Para comprender la puesta en marcha de este espacio de cine hay tres hitos fundamentales a tener en cuenta, que muestran diferentes dimensiones del cine y las luchas de los pueblos indígenas, y que articulan los distintos niveles de análisis (local, nacional e internacional). En primer lugar, un hecho puntual — pero fundamentalfue la entrevista a Melitona Enrique, sobreviviente de la masacre de Napalpí, realizada en enero de 2008 por Juan Chico, Lecko Zamora, Desiderio Lorenzo y David García, junto con Marcelo Pérez y Rafael Medina como técnicos audiovisuales. En segundo lugar, la creación del Instituto de Cultura del Chaco, que se diera en el marco de la Ley Provincial de Cultura — impulsada tras el cambio de Gobierno provincial de 2007_ , y

\footnotetext{
${ }^{15}$ Cabe aclarar que el financiamiento a través del Estado chaqueño no implica un ajuste de los contenidos. Ésa es una de las ventajas de realizar un cine, como lo expresa Alfonso Gumucio Dagron (2014), "de por sí invisible, tan invisible como las propias comunidades que representa".
} 
la creación, dentro de este instituto, del Departamento de Cine y Espacio Audiovisual (DeCEA) en el marco del crecimiento de la industria cinematográfica nacional. Por último, la organización del primer Festival de Cine Indígena en Chaco, en agosto de 2008, en el que el equipo del CEFREC de Bolivia impartió talleres de cine comunitario por primera vez en la zona.

\section{Lo local. Mostrar "la alegría de sobrevivir"}

En los primeros días de enero de 2008, algunos referentes indígenas se acercaron a Marcelo Pérez para pedirle si los podía acompañar a entrevistar a Melitona Enrique, una de las últimas sobrevivientes de la masacre de Napalpí. ${ }^{16 \text { " }}$. Ante este pedido, desde el DeCEA se organizó la visita, que tuvo lugar el 15 de enero de ese mismo año. Los entrevistadores fueron Juan Chico, Lecko Zamora, Desiderio Lorenzo, David García, acompañados por Teresa Artieda, mientras que Rafael Medina y Marcelo Pérez se encargaron de la parte técnica del registro audiovisual. "Estuvimos todo el día, desde temprano, hablando con ella; después nos invitó a comer. Entonces, de esa entrevista se sacó un video, y nos dio la posibilidad de decir realmente cómo fue, porque hay libros contradictorios", explicó Lecko Zamora. La entrevista fue editada por Alejandra Muñoz — integrante del equipo del DeCEA — y se titula Ra nqa' alaxa ÿo 'ot ra tonaxac (La alegría de sobrevivir) ${ }^{17}$. Tiene una duración de 6 minutos y muestra un fragmento de la entrevista en la que la protagonista recuerda la masacre, que tuvo lugar cuando ella tenía poco más de veinte años. La matanza indiscriminada de ancianos, niños y mujeres, el escape al monte de los sobrevivientes, los días de hambre y miedo que pasaron escondidos, la represión militar, la imposibilidad de enterrar a los muertos. "Murieron todas nuestras abuelas. ¡Qué se van a enfrentar a las armas de fuego! Iban cayendo las ancianas, que estaban cantando" — recuerda Melitona en la entrevista.

En ese año, Juan Chico y Mario Fernández — maestro bilingüe qom-, estaban por publicar el libro Napa'lpí. Ltaxayaxac yi ntago'q. Napa'lpí. La voz de la sangre, y ya habían entrevistado a Melitona sin poder guardar un registro audiovisual. Ese trabajo estaba orientado a la búsqueda de la visibilización de la historia reciente indígena, noción que proviene de los historiadores del siglo XX - del estudio de las guerras, totalitarismos, genocidios y crímenes contra la humanidad de ese siglo- (Franco y Levín, 2007). La historia es "reciente" no sólo por una escasa profundidad temporal:

\footnotetext{
${ }^{16}$ En 1911 se creó la Reducción Civil de Napalpí (hoy denominada Colonia Aborigen Chaco) del Territorio Nacional del Chaco. Una vez consumada la conquista militar del territorio chaqueño, las reducciones fueron utilizadas para restringir geográficamente a las poblaciones indígenas, a fin de llevar adelante la colonización con el asentamiento de población migrante y dar avance a la frontera agrícola. A comienzos de los 1920, los indígenas de Napalpí comenzaban a manifestarse en contra de las malas condiciones de vida asociadas al trabajo en la explotación algodonera; surgieron nuevos líderes religiosos y diferentes manifestaciones de descontento. Los terratenientes alertaron al gobernador del Territorio Nacional, Fernando Centeno, y, el 19 de julio de 1924, las Fuerzas Armadas aniquilaron a más de 400 indígenas, principalmente moqoit (mocovíes) y qom (tobas). Esta matanza es recordada como la masacre de Napalpí. Ver: Juan Chico y Mario Fernández (2008), Edgardo Cordeu y Alejandra Siffredi (1971), Nicolás Iñigo Carrera (1984) y Jorge Ubertalli (1987).

${ }^{17}$ Disponible en: https://www.youtube.com/watch?v=xtfwlX4pzhQ\&t=181s
} 
¿cómo definir qué es poco o mucho de acuerdo a la historia?, ¿a qué historia?, ¿con qué criterios?, ¿respecto a qué disputas de poder? Es reciente porque habla de pasados presentes, imborrables, pasados que no pasan (Conan y Rousso, 1994), "como algo atragantado en la garganta-memoria de sectores de la sociedad que no lo pueden dejar pasar-olvidar porque sí, así como así"18. Siguiendo a Enzo Traverso (2007) podríamos proponer que hay memorias oficiales, resguardadas por instituciones, incluso por los Estados, y memorias subterráneas, ocultas o prohibidas; memorias "fuertes" y "débiles" según las llama este autor. Habría que preguntarse en qué lugar de esa tensión entraría la historia indígena, la historia narrada por indígenas, a los que la noción disciplinar de historia ciertamente les es ajena, pero que están atravesados por estas memorias recientes imborrables. Un grupo de militantes por la "causa indígena"19" del que Juan Chico es referente imprimió en unas remeras Napalpí, memoria, verdad y justicia ${ }^{20}$, queriendo alertar sobre el ocultamiento de la historia de las masacres. Ese esfuerzo por hacer visible el ejercicio de la violencia de Estado llevó, a través de la entrevista a Melitona Enrique, a encontrar la posibilidad de otorgar un nuevo tipo de visibilidad, complementaria a la escritura.

En este sentido, los indígenas chaqueños dieron sus primeros pasos en el cine, porque encontraron en él una herramienta para dar testimonio de su historia, de las masacres de las que fueron víctimas. Juan Chico, quien nunca se interesó por aprender a utilizar la cámara, estuvo al frente del Área de Cine Indígena desde su inicio, porque el cine, en Chaco, es una herramienta más en la tarea de visibilizar un universo negado y olvidado por la historia y la sociedad argentina.

Juan Chico y Lecko Zamora - referentes del pueblo qom y wichí, respectivamente - ya habían trabajado juntos en acercar una reflexión sobre el mundo indígena chaqueño a distintos sectores de la población. Lecko Zamora me explicó que ambos, entre 2005 y 2007, habían llevado adelante la iniciativa de ir juntos a las universidades a encontrarse con estudiantes para discutir sobre filosofía y política, no desde una postura partidaria, sino en la búsqueda de generar un debate con los jóvenes universitarios en plena formación intelectual, con la expectativa de sensibilizar a aquellos que en unos pocos años serían los nuevos profesionales chaqueños. Lecko recordó la iniciativa con las siguientes palabras:

"Íbamos en el tiempo libre para compartir lo que nosotros hacemos, para visibilizar las cuestiones indígenas. Todos los argentinos peleando para que vengan... O hablar de Marx, de Mao y de todos esos, pero no saben nada de los indígenas, ¿no?

\footnotetext{
${ }^{18}$ Aquí estoy parafraseando a Mauro Greco, doctor en Ciencias Sociales (UBA), durante su exposición en el marco de ciclo de conferencias La maison divulga, Maison de l'Argentine, Paris, diciembre de 2016.

${ }^{19}$ Juan Chico, en reiteradas ocasiones, se ha referido a los reclamos indígenas y a la lucha por el reconocimiento como la "causa indígena" (conversaciones personales).

${ }^{20}$ En Argentina, esta expresión hace referencia a la utilizada en la lucha de los organismos de derechos humanos por el esclarecimiento de la desaparición forzosa de personas perpetrada por la última dictadura militar (1976-1983). A partir de ley 25.633 (2/08/2002) se creó el Día Nacional de la Memoria por la Verdad y la Justicia con el fin de conmemorar a las víctimas.
} 
Viva Perón, viva Evita y todo eso. O Ilia y qué se yo; Balbín, lo que quieras, ¿no? Pero no pasa nada con los indígenas $[\ldots]$ [Los estudiantes universitarios] siempre han seguido teorías foráneas, con diferentes concepciones políticas, filosóficas, que ellos aprenden en la Universidad, pero ni siquiera hacen cosas así - fuertes, grosas - para los pueblos indígenas, estando tan cerca. Y todo se debe a que es la Universidad. Y desde arriba empiezan a decir qué es lo que van a estudiar, qué es filosofía y qué no es filosofía y todas esas otras cosas [...] En este mar de confusión uno se agarra del tronco que se acerca, con el que cree que puede salvarse, con el que cree que puede flotar y que puede nadar. Entonces tratamos de llevar nuestro tronquito para que se agarren de ahí, o que vean que por lo menos estamos ahí, que hay un tronquito ahí que llamamos indígenas".

Esta actividad de visitar las facultades tuvo continuidad hasta 2007, cuando comenzó a gestarse el Instituto de Cultura de Chaco; Chico y Zamora abandonaron los pasillos de las facultades para abocarse a trabajar en esa nueva institución.

A diferencia de lo que ocurrió en la mayor parte de los países latinoamericanos, Argentina se construyó cómo Estado nación a partir de un discurso de borramiento de los indígenas; hubo una operación de tachado, de negación ${ }^{21}$. Como afirma Miguel Bartolomé (2003), “el mito de un inmenso territorio ‘desierto’ y sólo transitado por unas cuantas hordas de cazadores 'bárbaros' ha sido particularmente grato a la historiografía argentina, en tanto fundamentaba el modelo europeizante bajo el cual se organizó el proceso de construcción nacional". El avance agroganadero sobre territorios indígenas chaqueños desde finales del siglo XIX — a la par de la estabilización de las fronteras del Estado argentino- , con su consecuente desertización mediante el talado de bosques nativos y la sobreexplotación del territorio, llevó a que los sobrevivientes de las avanzadas militares tuvieran que optar entre resistir habitando en tierras inhóspitas, invisibilizarse en las periferias urbanas o insertarse forzosa y precariamente en el mercado laboral o en la red político-asistencialista de un Estado y una sociedad que les daba la espalda. La entrevista a Melitona Enrique, como primer hito de este cine local, fue un medio que se concibió para la visibilización de los genocidios perpetrados y de las formas de resistencia indígena; hacer cine se transformaba en una forma de reflexión y de registro del tiempo que pasa, y movilizaba a un colectivo de personas que, en marzo de 2008, empezó a participar del DeCEA y a iniciarse en el uso de las herramientas audiovisuales.

De esta manera, el dispositivo audiovisual se sumó a un abanico de otros dispositivos que se usaban para echar luz sobre distintas luchas y con miras a una autonomía y al desarrollo de una voz propia. Ya vimos que Juan Chico lo hizo a través de la escritura y que, junto con Lecko Zamora, se abocaron en esa misma dirección en el ámbito universitario. A su vez, desde finales de los años 1990, en El Impenetrable

${ }^{21}$ Al respecto ver Bartolomé, 2003, Briones, 2004; Lenton, 2005; Ramos, 2009. 
chaqueño se pusieron en marcha algunas radios indígenas. Bashe Charole, que formó parte de esa iniciativa, recuerda: "Fue ahí que empezamos a decir que está bueno ir tejiendo de a poco esta construcción de comunicación propia; hicimos todo un trabajo de hormigas, de muchos años, y recién en el año 2002 empezamos a hacer un proyecto más grande que tiene que ver únicamente con lo radial".

\section{El panorama nacional y la puesta en marcha de un espacio de cine indígena}

El 10 de diciembre de 2007, Jorge Milton Capitanich, del Frente para la Victoria ${ }^{22}$, asumió la gobernación de la provincia del Chaco. Este cambio de gestión ocurría a la vez que Cristina Fernández de Kirchner sucedía a su marido en la presidencia de la nación y ponía a los Gobiernos nacional y provincial bajo un mismo color partidario ${ }^{23}$, en un momento en el cual el kirchnerismo estaba fortalecido como fuerza política y en el que se evidenciaba un crecimiento económico. Esa coyuntura brindó la oportunidad de generar algunos cambios institucionales en la provincia y a la formación del Instituto de Cultura.

Hasta 2007, la gestión provincial de la cultura del Chaco había estado centralizada en la Subsecretaría de Cultura, que contaba con un reducido equipo de funcionarios. El cambio de Gobierno propició la reestructuración de esa área y un importante aumento de la inversión para su funcionamiento; se abrieron diferentes áreas de trabajo y se nombró a cargo de ellas a especialistas en cada tema. Marcelo Pérez - gestor cultural, cineasta y primer director de lo que sería el DeCEA— lo explicó de la siguiente manera: "De pasar de tener que hablar siempre con una sola persona para pedir intervención del Estado en nuestra actividad — que era la subsecretaria de Cultura-, pasamos a que los referentes culturales, o los hacedores culturales, tuvieran a alguien a quien dirigirse afín a su profesión [...] Eso vigorizó mucho la cuestión cultural en la provincia". Las personas que en un primer momento ocuparon estas áreas no eran necesariamente políticos que respondían a una estructura partidaria, sino especialistas competentes, lo cual dinamizó la gestión cultural provincial y propició el inicio de numerosos proyectos.

Es importante destacar que en Argentina, en los últimos veinte años, hubo muchos cambios políticos que dieron impulso a la industria cinematográfica y expandieron la diversidad de productos audiovisuales a lo largo del país. La Ley de Fomento y Regulación de la Actividad Cinematográfica (Ley No 24.377), aprobada en 1994 y reglamentada en 1995, fue una primera herramienta de activación del cine, en un momento en el cual la industria atravesaba una profunda crisis y a contrapelo de las medidas neoliberales tomadas en los años 1990 por el Gobierno nacional, que apuntaban a un retiro del Estado ante el avance de un mercado desregulado (Cáceres y Cáceres, 2012; Messuti, 2014). Con esta ley se quintuplicó el Fondo de Fomento y se agregó un subsidio por "otros Medios de Exhibición" (medios electrónicos). De todas

${ }^{22}$ Coalición partidaria predominantemente peronista (sus miembros pertenecían mayoritariamente al Partido Justicialista), creada en 2003 para lanzar la candidatura del presidente Néstor Kirchner (20032007).

${ }^{23}$ Los doce años anteriores (1995-2007) había gobernado la Unión Cívica Radical: Ángel Rozas (19951999 y 1999-2003) y Roy Nikisch (2003-2007). 
formas, las primeras ayudas que regulaba esta ley eran muy restrictivas en cuanto al tipo de películas que podían ser financiadas, ya que pocos directores y equipos técnicos cumplían con los requisitos de la denominada "primera vía" de fomento. Recién en 2004 se abrirían más vías de financiamiento para directores nóveles ${ }^{24}$, aunque el ingreso de proyectos que involucrara a realizadores que no hubieran realizado filmes comerciales seguía siendo restringido.

Una brecha se abrió con la incorporación de concursos, como "Historias Breves", "Telefilmes" u "Ópera Prima", en los que los requisitos de antecedentes eran mucho más flexibles. En 2008 se crearon concursos de adquisición de los derechos de exhibición televisiva de productos digitales y se sumaron nuevos formatos digitales dentro de los aceptados para la difusión. Durante ese último período, en la región del Noreste Argentino (NEA), surgió una red de realizadores y festivales, y, gracias a las oportunidades que añadía esa gama de financiamientos nacionales, ya no era obligatorio hacer cine desde Buenos Aires.

Por otro lado, la Ley de Servicios de Comunicación Audiovisual (Ley $\mathrm{N}^{\circ}$ 26.522) - mejor conocida como "Ley de Medios"-, sancionada en 2009, contempla la participación de los pueblos indígenas como realizadores y comunicadores. A partir de esta ley se incorporaron canales de televisión a la producción de films y se propició la exhibición de nuevos contenidos ${ }^{25}$. Varios comunicadores indígenas chaqueños participaron activamente de $\operatorname{los}$ foros $^{26}$ de discusión que se habían convocado antes de su tratamiento en el Congreso, y esa experiencia ayudó a formar y profundizar la mirada de éstos sobre el derecho a la comunicación y a generar alianzas a nivel nacional con otros pueblos. La Ley de Medios trajo muchas expectativas y también grandes desilusiones. Por un lado, nunca llegó a ponerse totalmente en vigor durante el Gobierno kirchnerista y, con el cambio de gestión de 2015, varios artículos fueron modificados por el Decreto Nacional de Urgencia 267/2015, en sintonía con las políticas neoliberales que buscaba implementar el Gobierno de Mauricio Macri ${ }^{27}$; se quitaron varias de las restricciones a la creación de oligopolios privados, con miras a una desregularización del mercado, y se otorgó a la comunicación la categoría de mercancía. En lo que concierne a los pueblos indígenas, la Ley de Medios, en su Título V, indica que el $10 \%$ de los fondos recaudados mediante gravámenes (Artículo № 97) debe ser

\footnotetext{
${ }^{24} \mathrm{La}$ tercera y cuarta vías de fomento, recién incorporadas, aceptaban películas dirigidas por personas que tuvieran "un filme estrenado comercialmente" — a diferencia de los cinco filmes exigidos por las vías anteriores-, y ya no se exigía demostrar la financiación de todo el proyecto en el momento de la presentación.

${ }^{25}$ Los productos audiovisuales del Plan Operativo de Promoción y Fomento de Contenidos Audiovisuales Digitales para TV se difundirían en distintas señales televisivas (ACUA, INCAA TV) a través del Banco Audiovisual de Contenidos Universales Argentino (BACUA) (Messuti, 2014).

${ }^{26}$ El proyecto de Ley fue enviado a la Cámara de Diputados el día 27 de agosto de 2009, tras los 24 foros y 80 charlas de discusión en todo el país, que junto con cartas y correos electrónicos generaron más de 15 mil opiniones, comentarios y sugerencias sobre el texto y derivaron en aproximadamente cincuenta modificaciones - aunque ninguna medular - al anteproyecto original (Fuente: Fernando Cibeira en: Diario Página 12: https://www.pagina12.com.ar/diario/elpais/1-130770-2009-08-28.html 28/08/2009)

27 Ver: Ley 27.078.
} 
destinado a "proyectos especiales de comunicación audiovisual y apoyo a servicios de comunicación audiovisual, comunitarios, de frontera, y de los Pueblos Originarios, con especial atención a la colaboración en los proyectos de digitalización". A su vez, bajo el Título IX — “Servicios de comunicación audiovisual de Pueblos Originarios"autoriza la instalación y el funcionamiento de servicios de radiodifusión AM y FM, así como de radiodifusión abierta. Lo cierto es que no hubo un real avance en ese sentido durante el kirchnerismo y, en la actualidad, nada indica que ese aspecto de la ley vaya a cumplirse.

En 2012 se lanzó el primer canal de televisión mapuche, Wall Kintun anunciado en un acto político el 7 de diciembre de $2012^{28}$ _, y seis meses después los miembros del consejo del canal denunciarían la falta de equipamiento, de entrenamiento audiovisual y de apoyo estatal en general. Si tenemos que analizar cómo el crecimiento de la industria audiovisual observado desde 2004 benefició a los pueblos indígenas, tendríamos que decir que lo hizo colateralmente: el estado de cosas generado propició la creación de festivales y el surgimiento de nuevos cineastas en la región del NEA, donde no había prácticamente producciones locales hasta fines de los años 1990. Muchos realizadores que habían migrado a Buenos Aires regresaron a sus provincias para hacer cine y, por otro lado, también cabe remarcar que el DCEA y sus festivales eran en parte financiados por el Instituto Nacional de Cine y Artes Audiovisuales (INCAA).

Como decía, la reactivación del cine argentino impulsó sólo colateralmente al cine indígena chaqueño. Para que el cine indígena diera sus primeros pasos fue imprescindible la trayectoria de distintos actores locales chaqueños, y entre ellos, Marcelo Pérez, quien en el año 1995 había comenzado a llevar el cine al interior de Chaco en su vehículo particular y proyectaba películas en las regiones inundadas. "Hubo una inundación; entonces yo agarré mi Jeep y llevábamos un televisor grandote, así, con una videocassettera VHS, e íbamos a los centros de inundados y les pasábamos películas a los chicos; eso fue como el puntapié inicial", me explicó. En el año 1997, la Subsecretaría de Cultura proveyó a Pérez y sus colaboradores de una camioneta para dar continuidad a esa tarea, y ese proyecto innovador se constituyó en uno de los antecedentes del Programa Nacional de Cinemóviles, lanzado en 1998 por el INCAA. Entre 1997 y 1999, Marcelo Pérez viajó a Buenos Aires para formarse en la Escuela Nacional de Experimentación y Realización Cinematográfica (ENERC) y, a su regreso, se integró al programa del que había sido precursor. Durante el período en que Pérez viajó proyectando cine por la provincia, también tuvo la oportunidad de dictar algunos talleres sobre el terreno, y, poco después, creó un departamento audiovisual en un centro de estudios de Resistencia. En 2007 fue convocado a presentar una propuesta para crear un área audiovisual en la Subsecretaría de Cultura; hasta ese momento no había un espacio de cine funcionando en la provincia y, como contó Pérez, "era una creación de cero, se iba a crear con la impronta de quien lo creara".

${ }^{28}$ Día en el que vencía el plazo determinado por la Corte Suprema de Justicia para la medida cautelar presentada por el Grupo Clarín - grupo económico que acapara una gran cantidad de medios de comunicación en Argentina - contra uno de los artículos de la Ley de Medios, por lo que ese día la normativa iba a entrar en vigencia plena. 
A comienzos de 2008 empezó a funcionar el Departamento de Cine y Espacio Audiovisual (DeCEA); Marcelo Pérez nos explicó que concibió este nombre de la siguiente manera: “De cine' involucraba todo lo que tenía que ver con el cine y la industria: industria internacional, industria nacional e industria local; el cine de todos aquellos profesionales que queremos vivir del cine como una profesión. Y el 'espacio audiovisual' abarcaba todo lo demás: el cine como inclusión social, el video educativo, el cine en las escuelas... Todos esos espacios eran el 'espacio audiovisual', es decir, había un concepto". En ese "espacio audiovisual” se crearía el Área de Cine Indígena, que dirigiría Juan Chico junto con un equipo de jóvenes comunicadores: Viyen Leiva, Bashe Charole, Aníbal Suárez y Diego Rivero, entre otros.

En el año 2007 se promulgó la Ley Provincial 6255 (Ley de Cultura) ${ }^{29}$, que permitió la creación del Instituto de Cultura de Chaco. Dentro de esa nueva estructura institucional, el DeCEA se convertiría en la Dirección de Cine y Espacio Audiovisual (DCEA), de la que Marcelo Pérez estaría al frente hasta el año 2011 - y el Área de Cine Indígena cambiaría también su estatus a Departamento de Cine Indígena- - La DCEA tuvo continuidad con el estatus de dirección hasta diciembre de 2015, cuando la nueva gestión $^{30}$ cambió el organigrama del Instituto de Cultura y la devolvió a su antigua, y más baja, jerarquía y, pasó a ser el Departamento de Cine, Audiovisuales y Artes digitales (DCAAD). ${ }^{31}$

Tabla $1^{32}$ :

\begin{tabular}{|c|c|c|c|c|}
\hline Período & Marco Institucional & Tipo de institución & Sigla & Cine indígena \\
\hline $\begin{array}{c}12 / 2007- \\
03 / 2008\end{array}$ & Subsecretaría de Cultura & Área de Cine & & \\
\hline $\begin{array}{c}03 / 2007- \\
04 / 2009\end{array}$ & $\begin{array}{c}\text { Subsecretaría de Cultura } \\
\text { (transición a Instituto de } \\
\text { Cultura) }\end{array}$ & $\begin{array}{c}\text { Departamento de Cine y } \\
\text { Espacio Audiovisual }\end{array}$ & DeCEA & $\begin{array}{c}\text { Área de Cine } \\
\text { Indígena } \\
\text { (gestión indígena) }\end{array}$ \\
\hline $4 / 2009-$ & Instituto de Cultura & Dirección de Cine y \\
$12 / 2015$ & Espacio Audiovisual & DCEA & $\begin{array}{c}\text { Departamento de } \\
\text { Cine Indígena } \\
\text { (gestión indígena) }\end{array}$ \\
\hline $\begin{array}{c}12 / 2015- \\
\text { presente }\end{array}$ & Instituto de Cultura & $\begin{array}{c}\text { Departamento de Cine, } \\
\text { Audiovisuales y Artes } \\
\text { Digitales }\end{array}$ & DCAAD & $\begin{array}{c}\text { Área de Cine } \\
\text { Indígena (gestión no } \\
\text { indígena) }\end{array}$ \\
\hline
\end{tabular}

\section{Tejiendo lazos con Latinoamérica: festivales, talleres de cine e intercambios entre pueblos}

Cuando se decidió en marzo de 2008 organizar un festival de cine, se lo concibió fuera de los parámetros habituales que caracterizan a este tipo de eventos,

\footnotetext{
${ }^{29}$ Reglamentada el 19 de abril de 2009

${ }^{30}$ Oscar Domingo Peppo sucedería a Jorge Milton Capitanich, ambos del Frente Para la Victoria.

${ }^{31}$ De aquí en adelante me referiré al espacio institucional DeCEA/DCEA/DCAAD, de acuerdo al período histórico al que se haga referencia. La tabla 1 tiene el fin de que las siglas que corresponda utilizar en cada caso sean de rápida comprensión para el lector.

${ }^{32}$ En esta tabla se resumen los nombres de las instituciones de cine de la provincia del Chaco desde 2007.
} 
generalmente anclados en centros urbanos y salas de cine. En sus comienzos, el Festival de Cine de los Pueblos Indígenas no se desarrollaba en una sola ciudad, sino que las proyecciones se realizaban en distintas localidades del interior de la provincia, en el seno de comunidades indígenas, y el último día se concluía con una "maratón", o "proyección de cine continuado", en Resistencia ${ }^{33}$. La idea era que el cine pudiera llegar a la mayor cantidad posible de personas, y con una selección internacional de películas que escaparan a los cánones establecidos de los festivales, en los que habitualmente se ponderan la excelencia técnica y el lenguaje audiovisual elaborado. Se buscó apuntar a lo que Salazar y Córdova (2008) entienden como cine imperfecto.

El INCAA realizaba todos los años un encuentro regional de "cinemovileros" 34 . Ese año - en el mes de agosto-, el encuentro sería en Chaco. Marcelo Pérez propuso a los cinemóviles de la región ${ }^{35}$ articular el encuentro con el $1^{\text {er }}$ Festival de Cine de los Pueblos Indígenas. Algunos comunicadores ${ }^{36}$ que ya venían implicándose en el quehacer audiovisual o radial se encargaron de la producción y del enlace con las comunidades que serían sedes del festival. En cada cinemóvil viajaba un maestro bilingüe como intérprete, que acompañaría los debates en la propia lengua indígena de cada zona. El festival tuvo su proyección inaugural en el Teatro Griego de la ciudad de General San Martín, para luego "recorrer pueblos y parajes, visitando unas 45 comunidades originarias del Chaco, en un recorrido de 6.500 kilómetros durante tres días" ${ }^{37}$, afirmaba la gacetilla de prensa. Marcelo Pérez nos explicó el costado militante y político que vehiculizaba la organización de estos festivales:

"El concepto era "cine indígena en las comunidades, para que las comunidades pudieran fortalecer procesos que vinieran llevando y vieran de qué manera pueblos de otros lugares han sobrellevado situaciones similares o problemas similares. Porque el festival era latinoamericano. Hicimos una convocatoria a toda Latinoamérica, a todos los países

\footnotetext{
${ }^{33}$ Este fue el formato del primer festival, que después se fue modificando y fue perdiendo progresivamente la itinerancia o, al menos, fue reduciendo su rango geográfico.

${ }^{34}$ Así se denomina a quienes conducen las camionetas del "cinemóvil" y proyectan los filmes en el marco del Programa Nacional de Cinemóviles.

${ }^{35}$ Participaron cinemóviles de Entre Ríos, Formosa, Tucumán, Corrientes y Chaco.

${ }^{36}$ La noción de "comunicador indígena" viene de la Coordinadora Audiovisual Indígena Originaria de Bolivia (CAIB) y de otras organizaciones que se articulan a través de la CLACPI. Esta noción define a los indígenas que buscan utilizar diferentes herramientas - la radio, la prensa, la escritura, el video, la televisión - para narrar, denunciar y tomar el control de la comunicación desde una mirada local, y para romper la mirada colonialista (Zamorano, 2009a y 2009b).

${ }^{37}$ Algunas de las comunidades visitadas fueron, en orden alfabético, 10 de Mayo, Barrio Mapic, Barrio Toba, Basail, Cacique Pelayo, Castelli, Colonia Aborigen, Colonia Matheu, Comandancia Frías, El Colchón, El Espinillo, El Pastoril, El Sauzalito, El Tabacal, Fortín Belgrano, Fortín Lavalle, General San Martín, La Tigra, Laguna Lobo, Laguna Pato, Las Palmas, La Sirena, Las Tolderías, Machagai, Miraflores, Nueva Pompeya, Pampa Chica, Pampa del Indio, Paraje Yatay, Sáenz Peña, San Bernardo, Siete Árboles, Techat, Villa Ángela, Villa Berthet, Villa Río Bermejito, Vizcacheral y Wichí-El Pintado (Fuente: http://festivaldecineindigenaenchaco.blogspot.com.ar/2008/10/chaco-argentina-del-5-al-9-deagosto-de.html).
} 
de Latinoamérica para que presentaran películas hechas por indígenas o con temáticas indígenas".

Los encuentros y proyecciones fueron espacios de debate, y estaba en el espíritu de la organización la intención de reunir a los tres pueblos indígenas reconocidos oficialmente por la provincia del Chaco: qom, moqoit y wichí. Un referente en cada zona $^{38}$ fue convocado para colaborar en la producción.

Los festivales fueron la ocasión de reunir a indígenas de distintas zonas de la provincia para el aprendizaje de herramientas audiovisuales, y de articular lo local con otras experiencias a nivel latinoamericano. Los primeros cuatro años se invitó al equipo del CEFREC, de Bolivia, para dictar talleres. El CEFREC, desde fines de 1980, ha ofrecido formación cinematográfica a pueblos indígenas y campesinos de ese país, y ha acompañado procesos de autonomía, con miras a promover la pluralidad de voces a través del audiovisual. Iván Sanjinés y Milton Guzmán fueron los representantes que llevaron adelante los talleres durante esos primeros años. Esos cursos estaban orientados a la enseñanza del uso de la cámara y de la técnica a través de la experiencia; se aprendía haciendo y mirando “'De una hora, veinte minutos de teoría y cuarenta de práctica', nos decían los del CEFREC”, recordó Juan Chico.

El primer taller tuvo lugar en Villa Río Bermejito (localidad ubicada en la región del Impenetrable) y en él se propuso profundizar en el conocimiento de quienes ya tenían experiencia e iniciar a nuevos jóvenes. Se rodaron cortometrajes basados en consignas de aprendizaje y se visionaron filmes locales y de tierras lejanas, tan lejanas como la China imperial de las películas de Zhang Yimou; se vio cine, mucho cine, y se intentó transmitir la experiencia de una manera amplia, mostrando la gran diversidad de posibilidades que existen para el abordaje de la construcción narrativa y estética. Paralelamente, el equipo del CEFREC intentó formar "comunicadores" que pudieran construir una mirada propia sobre la sociedad y que pudieran entender el cine como "un instrumento para empezar a descolonizar ciertas cosas con respecto al cine", según recuerda Juan Chico.

El equipo del CEFREC volvió en 2009 a dar un nuevo taller, esta vez en WichíEl Pintado ${ }^{39}$. En esta segunda etapa comenzó a gestarse el proyecto más ambicioso de concebir una película de ficción. Juan Carlos Martínez, moqoit de la zona de San Bernardo, fue el guionista que llevó a la pantalla una historia sobre el conflicto que atraviesan los jóvenes al tener que mediar entre el mundo criollo y el mundo indígena, sobre los consejos de los ancianos y sobre la vuelta a los ritos ancestrales a través de la danza y el espacio sagrado que representa para los moqoit la zona de meteoritos Campo del Cielo (González Zugasti, 2012; Giménez Benítez et al, 2000; López, 2011 y 2013). Este filme fue rodado en 2010 y se denominó La nación oculta ${ }^{40}$; es reconocido como

\footnotetext{
${ }^{38}$ Diego Rivero, de la zona qom de El Impenetrable; Rubén Lucas, de la zona wichí de El Impenetrable, y Juan Carlos Martínez, de la región moqoit cercana a San Bernardo.

${ }^{39}$ Un paraje que no alcanza a tener 800 habitantes, en la zona wichí de El Impenetrable chaqueño.

${ }^{40}$ El título completo de la película es La nación oculta en el meteorito. Aquí utilizamos la versión corta, porque es la forma en que sus realizadores se refieren al filme y como figura en la programación de los
} 
el primer largometraje de ficción producido por indígenas chaqueños. Fue editado por algunos comunicadores qom que viajaron en 2011 a La Paz (Bolivia) para formarse en esta área, y la película pudo ser estrenada en el festival indígena de ese mismo año, en una ceremonia organizada por distintos pueblos indígenas, en la que todos los participantes fueron homenajeados; una verdadera fiesta.

El festival de cine ha tenido continuidad los últimos nueve años, con la particularidad de ser muy cambiante en cuanto a su ubicación en el calendario, financiamiento y formato. En varias ocasiones, por cuestiones de producción, se movió su fecha de inicio - a veces, por la falta de celeridad de los organismos estatales para aprobar el presupuesto; otras, por las propias dinámicas del Instituto de Cultura y del DCEA - Hubo cambios y disputas que no desarrollaré aquí, pero, más allá de los vaivenes y de las modificaciones inesperadas, los organizadores han tratado de hacer coincidir los festivales con distintos eventos de importancia para los pueblos indígenas, esperando dar algún tipo de visibilidad a sus luchas ${ }^{41}$.

\section{¿Por fuera o por dentro del Estado?}

Cuando le pregunté a Juan Chico por qué insistían en trabajar desde el Estado, me respondió: “¿Por qué el Estado? Porque el Estado es el principal organismo que viola los derechos de los pueblos indígenas; o sea, en el marco de la reparación histórica, lo menos que pueden hacer es poner fondos y acompañar los procesos políticos realizativos". La charla derivó en contemplar las complejidades de ese vínculo y en un intento laberíntico de definir qué es "el Estado", y terminamos hablando sobre lo difícil que resulta, cuando se trata de iniciativas como el cine, salirse de la esfera estatal. De todas formas, trabajar en el Estado significa para algunos indígenas tener la posibilidad de cambiar las cosas desde adentro. Es interesante aquí hacer referencia a lo que González Zugasti (2012) expone en su trabajo con los moqoit, particularmente cuando conversa con Juan Carlos Martínez, guionista de La nación oculta, quien comenzó a trabajar dentro del Instituto de Cultura desde su creación. Martínez dice que un "choque de cosmovisiones se percibe en el carácter 'cuadrado' del Estado, es decir, su inflexibilidad, su postura inhumana y artificial, en contraposición con una visión indígena mucho más fluida y adaptable a la realidad". Su manera de mediar entre ese aparente choque es trabajar desde adentro para cambiarlo; su propuesta "no es la de destruir el Estado, o enfrentarlo directamente, sino la de aprovechar los espacios que éste ofrezca para ir transformándolo hacia un modelo diferente, un Estado verdaderamente pluricultural" (Íbid: 132-133).

Entender el vínculo entre indígenas chaqueños y Estado excede ampliamente el espacio aquí disponible. ${ }^{42}$ Siguiendo el eje que propone este artículo, quisiera dejar dos

festivales de cine indígena y en la videoteca del DCAAD.

${ }^{41}$ Algunos ejemplos son el 19 de julio, aniversario de la masacre de Napalpí, y el día del debate por la ley de educación bilingüe en la provincia de Chaco, en el que como actividad dentro del festival se organizó una discusión con comunicadores de diferentes procedencias (Chile, Bolivia, Colombia) en la Cámara de Diputados de la Provincia.

${ }^{42}$ Para tener una visión histórica de las políticas indigenistas del Estado provincial chaqueño habría que estudiar los distintos organismos creados para hacerse cargo de ellas, como la Dirección Provincial 
cosas planteadas: en primer lugar, que la apropiación de las herramientas audiovisuales por los indígenas chaqueños podría ser entendida en relación a un malestar mayor de estos pueblos en cuanto a un diálogo asimétrico, en un marco histórico colonialista que les impone la definición de quiénes y cuáles son sus necesidades, sin permitirles un "derecho a réplica" para expresarse por sí mismos.

En general se mira con sospecha el rol de los intermediarios en su vínculo con el Estado y la sociedad envolvente, que coloca a los indígenas en el lugar de quienes tienen que ser "tutelados" por personas "mejor capacitadas" que puedan interceder por ellos. Lecko Zamora lo explicó así:

"Siempre, para hacer cualquier cosa indígena tiene que haber un Tarzán, un Superman, qué sé yo, un intermediario, ¿no? Siempre han sido los curas, los antropólogos, los sociólogos. $\mathrm{Y}$ en este caso podemos trabajar con cualquiera, pero vamos a hablar y vamos a consensuar qué es lo que vamos a hacer y qué es lo que nos parece a nosotros. [Los agentes del Estado sostienen que] "los indios todavía no están preparados para hacer eso, entonces somos necesarios. Y así siguen los años, ¿no?; entonces son cuestiones que uno mira".

En este sentido, la formación de un espacio de cine indígena en el DCEA se planteó como una posible vía para equilibrar ese diálogo siempre desbalanceado, y algunos indígenas vieron allí la oportunidad de resistir a la forma en que se tomaban las decisiones, sin consultarlos ni hacerlos partícipes; ese espacio, sin embargo, también generó varias rupturas a nivel interétnico. Para Juan Chico, Marcelo Pérez supo ver que "no podemos seguir trabajando para los indígenas y sin los indígenas". De esa manera, el Departamento de Cine Indígena contribuyó a la autonomía en la construcción de los discursos que los representan.

En segundo lugar, quisiera dejar claro que existieron varias iniciativas organizativas - de mayor y menor envergadura - que buscaron alternativas al trabajo vinculado al Estado provincial. En 2009, durante los talleres de Wichí-El Pintado, los comunicadores indígenas chaqueños formaron la CAIA (Coordinadora Audiovisual Indígena Argentina). La creación de ese espacio fue motivado por la gente del CEFREC, quienes transmitieron la experiencia boliviana de la CAIB, fundada en 1996 a fin de poder coordinar las actividades que los comunicadores realizaban en distintos puntos del país ${ }^{43}$. En Chaco, esta organización fue pensada como un espacio de autonomía con respecto de las estructuras estatales que, gestionada por indígenas y sin intermediarios, pudiera articular los trabajos de búsqueda de financiamiento (paradójicamente, hasta el presente sólo ha conseguido financiamiento

del Aborigen — creada en 1956 por el interventor nacional coronel Pedro Avalía—, que en 1987 sería reemplazada por el Instituto del Indígena Chaqueño (Carrasco y Briones, 1996), así como una compleja red de organizaciones religiosas, partidos políticos y ONG (Lenton, 2015).

${ }^{43}$ Los trabajos del CEFREC y de la CAIB se articulaban en el marco de un plan nacional de comunicación indígena (Zamorano, 2009). 
del Estado) ${ }^{44}$. La CAIA sirvió para dar visibilidad a los indígenas argentinos a nivel internacional. "Los del CEFREC nos contaban que en los encuentros que había en la región nunca había gente de Argentina, como también nos hablaban de ese discurso de que 'en Argentina no había indígenas'; entonces, un poco para visibilizar”, explicó Juan Chico. La creación de esta coordinadora les permitió asistir a festivales nacionales e internacionales, en representación de un colectivo de comunicadores.

En el año 2012 se dio un debate al interior de la CAIA con la idea de darle alcance nacional a esta agrupación, pero no se logró el consenso absoluto; un $60 \%$ de los participantes votó a favor y se creó la Coordinadora de Comunicación Audiovisual Indígena Argentina (CCAIA). Algunos de los que estuvieron en desacuerdo, y que formaban parte de la Asociación Comunitaria Indígena de Comunicación (ACIC) — fundada con anterioridad a la CAIA, en 1999- continuaron su tarea por fuera de la coordinadora y obtuvieron la personería jurídica como asociación en 2013. Este grupo escindido, actualmente conformado por 27 comunicadores, siguió trabajando principalmente en la zona de El Impenetrable.

Desde 2011, el Estado ha ido reduciendo progresivamente el apoyo económico al Festival de Cine de los Pueblos Indígenas, y ya no se pueden afrontar visitas internacionales, proyecciones en el interior de la provincia ni el pago de premios. Según Marcelo Pérez, "el Estado, a través de la DCEA, se retrajo en cuanto al apoyo — no fue el mismo en 2008 que en 2011, en 2012 o en 2013 - y esa asociación [la coordinadora indígena] no tuvo las posibilidades, digamos, de comandar el proceso; entonces es como que empezó a flaquear, ante la ausencia del Estado”.

\section{El cine, ¿una herramienta de lucha?}

Si nos acercamos a la diversidad de experiencias de cine indígena en Latinoamérica, resulta complejo comprender en qué sentidos este cine puede servir como "herramienta de lucha". En rasgos generales, el cine de lucha o militante está asociado al documental, que registra procesos sociales de primera mano para evidenciar conflictos. El docudrama y la docuficción ${ }^{45}$, géneros muy utilizados en Bolivia desde el CEFREC-CAIB (Zamorano, 2009; Schiwy, 2009), han servido también como medio de denuncia y de visibilización de problemáticas sociales.

\footnotetext{
${ }^{44}$ Las distintas escuelas de formación de cineastas indígenas de Latinoamérica, al menos las que se han sostenido en el tiempo -Video nas aldeias en Brasil (Carelli, 2013; Aufderheide, 2008) y Promedios comunicación en México, entre otras- , han trabajado por fuera del Estado y han sido financiadas por organismos internacionales. Por lo general, las experiencias financiadas totalmente por el Estado no han perdurado, como el caso del programa Transferencia de Medios Audiovisuales a Comunidades y Organizaciones Indígenas (TMA), dependiente del Instituto Nacional Indigenista de México, que ha sido borrado de un plumazo por los cambios de la coyuntura política (Wortham, 2005 y 2013).

${ }^{45}$ En este caso los realizadores ficcionalizan situaciones de la vida real, y la ficción funciona como un espacio idóneo para denunciar, pero sin criminalizar a los individuos ni a las instituciones implicados en conflictos, además de mostrar realidades que desde el documental en primera persona podrían generar efectos disruptivos no deseados.
} 
Durante 2014 visité en dos oportunidades la Cordillera del Cóndor (Amazonía ecuatoriana), donde el pueblo shuar se encuentra amenazado ante el avance de la minería extractivista sobre su territorio. El proyecto Etsa-Nantu/Cámara-Shuar ${ }^{46}$, en el que participo, es una respuesta a la demanda de las comunidades de aprender a usar cámaras como herramientas de denuncia a la violencia de la que son objeto. Sorprendentemente, cuando llegamos a dar los talleres al centro Kupiamais ${ }^{47}$, nos propusieron filmar ficciones: historias ancestrales shuar que formaban parte de su universo mítico. Para ello necesitaban aprender a escribir un guión (narrativo y técnico), a diseñar escenografías e, incluso, a realizar algunos "efectos especiales" ${ }^{48}$ La pregunta que se impuso fue: ¿por qué un pueblo que tiene enfrentamientos con el Estado - incluido el Ejército- y con megaempresas multinacionales decide contar historias mitológicas? Aquí se planteó la urgencia por un cine que recupere historias que se "están yendo": si falleciera esa abuela de más de 90 años de la cual se tomó el relato para hacer la película, ya no podríamos contar ese mito —o al menos no esa versión-.

A través de ese cine se busca que alrededor de un televisor de 14 pulgadas, como el que teníamos en la selva, esas historias lleguen a las nuevas generaciones. Como me dijo un joven de Pampa del Indio (Chaco) durante los talleres de cine del Festival de Cine de los Pueblos Indígenas de 2015, "la televisión ha reemplazado al fogón, momento en que los abuelos nos contaban historias; ahora, las familias nos reunimos en torno a la televisión por las noches, y lo que queremos nosotros es "descolonizar" esa televisión para seguir aprendiendo nuestras historias". Juan Chico, para quien no se ha llegado a cumplir el objetivo de que la "cámara esté al servicio de la lucha del pueblo" en un sentido extenso, recordó:

"La única que vez que [...] se usó la cámara como herramienta de lucha fue cuando querían llevar el meteorito a Alemania ${ }^{49}$. Claro, porque como ya teníamos editada La nación oculta, la trajimos acá, a la plaza y la mostramos. "Mirá, no queremos que se lleven el meteorito porque los moqoit dicen esto". Entonces se mostraba el documental, y eso me acuerdo que frenó, eso me acuerdo que nos llevó a tener una reunión con el gobernador. Vinieron los referentes moqoit y le dijeron: "No queremos que lleven el meteorito por esto, por esto y por esto". Ahí sí yo vi como esta película ayudó a la lucha o a reivindicar, en este caso, los meteoritos del Chaco".

\footnotetext{
${ }^{46}$ Más información en: www.camara-shuar.org

${ }^{47}$ Comunidad de unos 200 habitantes ubicada en el cantón de Gualaquiza.

${ }^{48}$ La película realizada se titula Tsunki aumatsamu, el mito de Tsunki (2015), disponible en: https://vimeo. com/113070917.

${ }^{49}$ A fines de 2011 se desató una intensa polémica por el intento del traslado de uno de los meteoritos de Campo del Cielo a Kassel, Alemania, para una exposición en la que participarían los artistas plásticos Guillermo Faivovich y Nicolás Goldberg. La comunidad académica presentó una carta en estos términos: "Creemos firmemente que este proyecto implica un modo profundamente colonialista de vincularse con las riquezas y valores del Chaco. En lugar de 'trasladar' una pieza como una suerte de 'curiosidad cósmica' sería mucho mejor que quienes tienen los fondos y el prestigio buscaran promover su puesta en valor en el lugar de origen" (enero de 2012).
} 
En este caso también una ficción plasma la importancia de ciertos espacios sagrados, como lo es Campo del Cielo (López, 2009 y 2013; González Zugasti, 2012), y trasforma una película en una herramienta de lucha. Por ello cabe preguntarse cómo se construye lo urgente y cómo un documento audiovisual puede cambiar su sentido y tornarse militante dependiendo del contexto social, histórico y político. Los referentes shuar que quisieron filmar historias míticas tuvieron esa visión; recientemente uno de ellos me contó que escribió un nuevo guión, sobre el mito de Nunkui, en medio del despliegue de violencia militar que amenaza a la comunidad; su ímpetu y su visión que me resultan admirables.

El cine de ficción también permite a los indígenas recrear sus universos ancestrales, universos que son disonantes con la realidad que les toca vivir en el mundo contemporáneo; la imagen audiovisual es un espacio para reivindicarlos y reinventarlos, para pensar la estética de la imagen y transmitir sus concepciones de mundo, ese mundo ancestral al que tanto hacen referencia en sus relatos ${ }^{50}$. En Chaco, durante la filmación de La nación oculta, en las proximidades de San Bernardo, los realizadores tuvieron especial cuidado al recrear el espacio. Juan Chico nos contó: "Había que hacer las tomas - para el rodaje - en el campo, en el monte, y el problema era que la gente no tenía monte (¡no tenemos monte!). Entonces tuvimos que pedir prestado un campo a un señor; sí, para filmar. Impresionante, eso. Y eso también animaba, porque siempre la idea era que la herramienta audiovisual tuviera un propósito y que pudiera servir a la lucha o a la causa". La invención de la imagen cinematográfica abre la posibilidad de reapropiarse simbólicamente de lo perdido: el territorio, las danzas, las vestimentas. La cámara opera sutilmente de forma contestataria al decir "esto somos" o "esto queremos seguir siendo" 51 . El territorio expropiado, los ritos, la tradición oral pueden plasmarse a través de las cámaras en imágenes, controladas y cuidadas por aquellos que recuerdan y reinventan sus historias. Por un lado, exponer esos universos en el rectángulo plano de la pantalla tal vez parezca poco para luchar por el reconocimiento y la autodeterminación, sobre todo si faltan interlocutores dispuestos a comprender ese mensaje, pero, por otro lado, hacer cine para los "otros" - los occidentales - también pone en una disyuntiva difícil de resolver a los nóveles cineastas indígenas chaqueños. Reinventar esos mundos sin restricciones puede ser una forma "militante" de protegerlos, una manera de atesorar historias que tal vez algún día sean también una herramienta de lucha.

En estas palabras de Lecko Zamora se sintetiza de algún modo el sentido que se le dio al cine indígena en Chaco en esta primera etapa, sin los rodeos que la escritura académica implica:

"Sí, yo pienso que la cámara es un arma, en el buen sentido de la palabra, de protección o de defensa, y va a depender de la misma gente dónde enfocar su trinchera, porque no sólo

\footnotetext{
${ }^{50}$ Durante los rodajes con los shuar, la escenografía de la selva era cuidada en cada plano; no debíamos mostrar un solo árbol cortado con motosierra ni tampoco un banano, ni una prenda occidental, ni marcas del contacto con el mundo mestizo, ya que esos elementos romperían la recreación del universo mítico buscado.

${ }^{51}$ Parafraseando aquí a Ana Zanotti, antropóloga y documentalista de la provincia de Misiones.
} 
están invadiendo el espacio exterior del territorio, sino que también hay una invasión en el territorio cultural, mental. Nosotros, los pueblos indígenas, todavía estamos colonizados; nosotros no disponemos ni podemos hacer lo que nosotros queremos, porque todo se fundamenta un poco en la economía; porque si alguien, como antes, podía enseñar a los chicos una determinada cosa, como el tejido y todo eso, era porque ellos tenían asegurada la comida todos los días, pero ahora que nos quitaron el monte... Destrozaron todo el bosque y con eso se fueron los animales, las aves e incluso los peces, que están cada vez más difíciles. Esta es otra manera de seguir matando a los pueblos indígenas, no solamente en la forma física, o sea, el genocidio, sino también está la otra parte, la de mantenerlos en un estado de dependencia. Al final, uno tiene que atenerse a lo que le den, porque no tenemos esa libertad, ni siquiera la propia tierra, en la que hace miles de años que estamos. Pero al crear un nuevo Dios al que le llaman Estado, que hace y dispone a través del Olimpo de la gente que nosotros elegimos cada cuatro años y que sin consultar con nosotros... Si me dan una herramienta para hacer algo, capaz que lo que más me preocupa es que mi cultura se está yendo. Porque la otra parte, bueno, más o menos uno la controla, y uno sabe que si uno se opone va a haber muertes y todo eso, ¿no? Entonces, uno busca siempre cómo sobrevivir, o supervivir. Entonces capaz que es más inteligente eso de mantener la cultura, que es lo más valorable de nosotros".

La libertad que otorgaba el propio territorio que ya no está, la colonización de la mente, la imposibilidad de resistir ante la violencia, la necesidad de adaptarse para sobrevivir se sintetiza en estas palabras donde la cámara reaparece como una "herramienta para hacer algo" respecto a este desolador paisaje. Cuando Worth y Adair se acercaron en 1966 a la comunidad navajo de Pine Spring para enseñarles a usar cámaras, pidieron el consejo de Sam Yazzie, un referente de la comunidad. Éste les preguntó: “¿Realizar filmes les hará mal a las ovejas?”. A lo que Sol Worth respondió que no había chance de que algo malo les ocurriera a las ovejas si realizaban cine. Entonces, Yazzie replicó “¿Hacer filmes les hará bien a las ovejas?”. Y ante una nueva negativa el anciano volvió a preguntar: “Entonces, para qué hacer películas?"52 (Worth y Adair, 1972: 4). Esta pregunta sigue resonando aún hoy y, tras 50 años de cine indígena, sería aún difícil de responder. Margaret Dubin (1998: 74) planteó que reemplazar el término "ovejas" por "cultura indígena" nos permitiría debatir si este cine no corre el riesgo de generar un nuevo tipo de dependencia para los pueblos que lo realizan ${ }^{53}$.

\footnotetext{
${ }^{52}$ La traducción es propia.

${ }^{53}$ Ver: al respecto las discusiones propuestas por Turner (1992 y 1997), Faris (1993 y 1997) y Ginsburg (1991).
} 
Considerar que el cine realizado por indígenas es de por sí descolonizador nos pone en riesgo de invisibilizar otras formas en las que el colonialismo opera. Por otra parte, a los filmes realizados por indígenas muchas veces se les exige que se ajusten a una idea arbitraria de "autenticidad", que representen una mirada del mundo "verdaderamente" indígena y radicalmente distinta a la ofrecida por el cine occidental, que estén construidos a imagen y semejanza de lo que Occidente quiere ver y oír sobre ellos. Recuerdo aquí una película rodada por mbya guaraníes titulada Mokoi Tekoá Petei Jeguatá - Duas aldeias, uma caminhada (Dos aldeas, una caminata), en el que los turistas les preguntan a los mbya si las plumas de sus artesanías eran de aves salvajes o de gallinas, y Ariel Ortega, uno de los directores del filme, se interpela: “¿Tenemos que matar a los pájaros sólo para poder venderlos?". Con esto cabe plantearse si esta misma exigencia recae en el cine, que debe ofrecer la imagen de lo que Occidente espera que un indígena filme, o mismo debe cumplir las expectativas de ser un cine militante, o portar "gramática" radicalmente novedosa para la mirada occidental.

Tras este recorrido sobre las distintas instancias sociales y políticas que acompañaron el surgimiento del cine indígena en Chaco, podemos argüir que, en la medida en que se les permita a los indígenas una real autonomía en el manejo de la imagen y de la narrativa audiovisual, las experiencias realizativas van a seguir abriendo vías fecundas de expresión y de lucha. Faye Ginsburg propone que estos medios indígenas, junto con el cine etnográfico, "intentan comunicar algo sobre esta identidad social o colectiva que llamamos "cultura", a fin de mediar (eso se espera) a través de las brechas de espacio, tiempo, conocimiento y prejuicio" 54 (1991: 104). La autonomía en la toma de decisiones y en la construcción de discursos es necesaria para que esta herramienta expresiva pueda ser usada en la creación de un espacio de libertad, sin sujeción a las miradas colonialistas.

\section{Referencias bibliográficas}

Aufderheide, P. 2008. "You See the World of the Other and You Look at Your Own. The Evolution of the Video in the Villages Project". En: Journal of Film and Video, No 60, pp 26-34.

Aumont, J. 2011. Les théories des cinéastes. A. Colin, Paris.

Bartolomé, M. 2003. “Los pobladores del 'Desierto' genocidio, etnocidio y etnogénesis en la Argentina”. Cuadernos de Antropología Social FFyL - UBA 17, 162-189.

Bengoa, J. 2009. ¿Una segunda etapa de la Emergencia Indígena en América Latina? Cuadernos de Antropología Social FFyL - UBA 29, 7-22.

Briones, C. 2004. "Construcciones de aboriginalidad en Argentina”. Société suisse des Américanistes / Schweizerische Amerikanisten-Gesellschaft 73-90.

Cáceres, A., Cáceres, C. 2012. El cine ha muerto. ¡Larga vida al cine! El Plan de Fomento del INCAA ante el desarrollo de la tecnología HD. Revista Toma Uno $1,177-190$.

\footnotetext{
${ }^{54}$ La traducción es propia.
} 
Carelli, V. 2011. “Um novo olhar, uma nova imagem”. En: Vídeo nas Aldeias Project (ed.) Vídeo nas aldeias, 25 anos: 1986 - 2011, Olinda, Vídeo nas Aldeias.

Carelli, V. 2013. "Video nas aldeias, una propuesta de seducción cultural". En: Revista Chilena de Antropología Visual, № 21, pp, 51-63.

Carrasco, M. y Briones, C. 1996. La tierra que nos quitaron, Buenos Aires, IGWIA y Lhaka-Honhat.

Carvalho, A.; De Carvalho, E.I. y Carelli, V. 2011. Video nas aldeias, 25 anos: 1986 2011, Olinda, Vídeo nas Aldeias.

Chico, J. y Fernández, M. 2008. Napa'lpí. Ltaxayaxac yi ntago'q. Napa 'lpí. La voz de la sangre, Resistencia, Instituto de Cultura del Chaco.

Chomsky, N. 1979. Sintáctica y semántica en la gramática generativa, Ciudad de México, Siglo XXI Editores.

Conan, E. y Rousso, H. 1994. Vichy: un passé qui ne passe pas, Pour une histoire du XXe siècle, París, Fayard.

Cordeu, E.J. y Siffredi, A. 1971. De la algarroba al algodón, Buenos Aires, Juárez Editor. Cordova, A. 2011. "Estéticas enraizadas: aproximaciones al video indígena en América Latina". En: Comunicación y Medios, № 24, Santiago, Universidad de Chile, pp 81-107.

Dubin, M. 1998. "From Artful Ethnography to Ethnographic Art: The Enduring Significance of the Navajo Film Project". En: Visual Anthropology Review, Vol. 14, No 1 , pp 73-75.

Edwards, E. (Ed.), 1997. Anthropology and photography: 1860-1920. Yale Univ. Press [u.a.], New Haven.

Faris, J. F. 1993. "Response to Terence Turner”. En: Anthropology Today, No 9, pp 12-13. Faris, J. F. 1997. “Comentaire dans J. Weiner: 'Televisualist Antrhopology. Representation, Aesthetics, Politics"”. En: Current Anthropology, № 38, pp 211-213.

Franco, M. y Levín, F. (eds.) 2007. Historia reciente: perspectivas y desafios para un campo en construcción, Buenos Aires, Paidós.

Gauthier, J. 2008. "“Lets others speak for us': The neglected roots and uncertain future of Maori Cinema in New Zeland”, en: Wilson, P., Stewart, M. (Eds.), Global Indigenous Media. Cultures, Poetics and Politics. Duke University Press, Durham, pp. 58-73.

Giménez Benítez S.; Lopez A. y Mammana, L. 2000. "Meteorites of Campo del Cielo: Impact on the Indian Culture". En: César Esteban y Juan Antonio Belmonte (comp.) Astronomy and Cultural Diversity. Presented at the Proceedings of the International Conference Oxford VI and SEAC 99, La Laguna, Organismo Autónomo de Museos del Cabildo de Tenerife.

Ginsburg, F. 2011. "Native Intelligence: A Short History of Debates in Indigenous Media and Ethnographic Film". En: Marcus Banks y Jay Ruby (eds.) Made to Be Seen: Perspectives on the History of Visual Anthropology, Chicago, University of Chicago Press.

Ginsburg, F. 1991. "Indigenous Media: Faustian Contract or Global Village. En: Cultural Anthropology, № 6, pp 92-112. 
Ginsburg, F.; Abu-Lughod, L. y Larkin, B. (eds.) 2002. Media Worlds: Anthropology on New Terrain, Berkeley, University of California Press.

Giordano, M. 2012. “Someter por las armas, vigilar por la cámara: Estado y visualidad en el Chaco indígena". En: Sociedade e Cultura, № 14.

Giordano, M. 2004. Discurso e imagen sobre el indigena chaqueño, La Plata, Ediciones Al Margen. González Zugasti, E. A. 2012. "Todavía estamos vivos": procesos identitarios y de resistencia étnica entre los mocovíes del suroeste chaqueño en los últimos cuarenta años. Programa de Posgrado en Antropología Social Universidad Nacional de Misiones.

Gumucio Dagron, A. (ed.) 2014. Cine comunitario en América Latina y el Caribe, Bogotá, Fundación Nuevo Cine Latinoamericano.

Gustavsson, A. y Giordano, M. 2013. "The Pilagá of the Argentine Chaco through an Exoticizing and Ethnographic Lens: The Swedish Documentary film 'Following Indian Trails by the Pilcomayo River'". En: Journal of Aesthetics \& Culture, No 5. Gustavsson, A y Giordano, M. 2012. "El documental etnográfico de Wilhelm Hansson y Mauricio Jesperson. Registros del indígena chaqueño para un público europeo”. En: III Congreso Internacional de la Asociación Argentina de Estudios de Cine y Audiovisual, Universidad Nacional de Córdoba, mayo 10-12, 2012; Córdoba, Argentina.

Jackson, J.E., Warren, K. B. 2005. "Indigenous Movements in Latin America, 1992-2004: Controversies, Ironies, New Directions". Annual Review of Anthropology 35, 549-573.

Lenton, D. 2015. "Notas para una recuperación de la memoria de las organizaciones de militancia indígena". Identidades 8, 117-154.

Lenton, D. 2005. De centauros a protegidos. La construcción del sujeto de la política indigenista argentina desde los debates parlamentarios (1880 - 1970). Universidad de Buenos Aires, Buenos Aires.

López, A. M. 2009. La Virgen, el Árbol y la Serpiente. Cielos e identidades en comunidades mocovies del Chaco, tesis (doctorado en Antropología), Buenos Aires, Universidad de Buenos Aires.

López, A. M. 2011. "New Words for Old Skies: Recent Forms of Cosmological Discourse among the Aboriginal People of the Argentinian Chaco". En: International Astronomical Union, № 7, pp 74-83.

López, A. M. 2015. "Astronomical Heritage and Aboriginal People: Conflicts and Possibilities". En: International Astronomical Union, No 11, pp 142-145.

Messuti, P. 2014. El impacto de la digitalización en la industria del cine argentino: Políticas de fomento, dinámicas productivas y nuevas ventanas de exhibición. Hipertextos 2, 23-42.

Pearson, W. G. (ed.) 2015. Reverse Shots: Indigenous Film and Media in an International Context, Film and Media Series, Waterloo, Wilfrid Laurier University Press.

Peterson, L. C. 2011. “'Reel Navajo': the linguistic creation of indigenous screen memories". En: American Indian Culture and Research Journal, No35, pp 111-134.

Peterson, L. C. 2013. "Reclaiming Diné Film: Visual Sovereignty and the Return of 'Navajo Film Themselves ,’. En: Visual Anthropology Review, № 29, 29-41. 
Raheja,M.H.2013.Reservation Reelism: Redfacing, Visual Sovereignty, and Representations of Native Americans in Film. Lincoln, University Of Nebraska Press.

Ramos, A. R. 2009. "O indigenismo na montagem da naçao. Contrastes e converências entre Brasil e Argentina”. Anuario Antropológico/2007-2008 27-59.

Rousso, H. "La trayectoria de un historiador del tiempo presente, 1975-2000". En: Anne Pérotin-Dumon (ed.) Historizar el pasado vivo en América Latina [En línea], puesto en línea en 2007, consultado el 29 de diciembre de 2016. URL: http://historizarelpasadovivo.cl.

Salazar, J. F. 2002. "Activismo indígena en América Latina: estrategias para una construcción cultural de las tecnologías de información y comunicación”. JILAS Journal of Iberian and Latin American Studies 8, 60-80.

Salazar, J. F. 2004. Imperfect Media: The Poetics of Indigenous Media in Chile, Sydney, University of Western Sydney.

Salazar, J. F. y Cordova, A. 2008. "Imperfect Media and the Politics of the Poetics of Indigenos Video in Latin America". En: Pamela Wilson y Michelle Stewart (eds.) Global Indigenous Media: Cultures, Poetics, and Politics. Durham, Duke University Press.

Schiwy, F. 2009. Indianizing film: decolonization, the Andes, and the question of technology. Rutgers University Press, New Brunswick, N.J.

Traverso, T. 2007. "Historia y memoria. Notas sobre un debate". En: Marina Franco y Florencia Levín (eds.) Historia reciente: perspectivas y desafíos para un campo en construcción, Buenos Aires, Paidós.

Turner, T. 1992. "Defiant Images. The Kayapo Appropriation of Video". En: Anthropology today, No 8, pp 5-16.

Turner, T. 1990. “The Kayapo Video Project: a Progress Report”. En: Commission on Visual Anthropology Review, otoño, pp 7-10.

Ubertalli, J. L. s.n. Guaycurú, tierra rebelde, Buenos Aires, Antarca.

Vickers, S. B. 1998. Native American identities: from stereotype to archetype in art and literature, $1 \mathrm{st}$ ed. ed. University of New Mexico Press, Albuquerque.

Wilson, P. y Stewart, M. (eds.) 2008 Global Indigenous Media: Cultures, Poetics, and Politics, Durham, Duke University Press.

Worth, S. y Adair, J. 1970. "Navajo Filmmakers". En: American Anthropologist, No 72, 9-34.

Worth, S. y Adair, J. 1972. Through Navajo Eyes; An Exploration in Film Communication and Anthropology. Bloomington, Indiana University Press.

Wortham, E. C. 2004. "Between the State and Indigenous Autonomy: Unpacking Video Indígena in Mexico". En: American Anthropologist, № 106, pp 363-368.

Wortham, E. C. 2013. Indigenous Media in Mexico: Culture, Community, and the State, Durham, Duke University Press.

Zamorano Villarreal, G. 2009a. "Intervenir en la realidad": usos políticos del video indígena en Bolivia. En: Revista Colombiana de Antropología, № 45, pp 259-285. Zamorano Villarreal, G. 2009b. Reimagining Politics: Video and Indigenous Struggles in Contemporary Bolivia, New York, New York University. 
Zamorano Villarreal, G. "Los usos del video comunitario para imaginar un Estado plurinacional" [en línea]. Puesto en línea s.f., consultado 15 de diciembre de 2016. URL: http://www.bolivianstudies.org/revista/9.1/documentos_pdf/ ZamoranoGabriela42712.pdf.

\section{Filmografía}

Beckham, M. 1989. Kayapo: Out of the Forest. Disappearing World Series. $51 \mathrm{~min}$.

Chico, J.; Zamora, L.; David, G.; Desiderio, L. y Gladys, P. 2008. Ra nqa' alaxa yo'ot ra tonaxac (La alegría de sobrevivir). 6 min.

Duarte Ortega, A.; Beñites, G. y Ramos Morinico, J. 2008. Mokoi Tekoá Petei Jeguatá (Duas aldeias, uma caminhada). $63 \mathrm{~min}$.

Etsa-Nantu Cámara Shuar. 2015. Tsunki aumatsamu, el mito de Tsunki. 18 min.

Martínez, J.C. 2011. La nación oculta. 39 min. 